\title{
Participating in the MRCPsych examinations: the patients' experience
}

\author{
Darina Sloan, Laura Mannion, Gregory Swanwick and James O'Boyle
}

\begin{abstract}
Candidates' views regarding examinations in psychiatry have been highlighted in recent years. Few studies to date, however, have examined the views of the patients themselves foward the examination procedure. This study examines the knowledge and experience of a patient group participating in the College membership examinations. Providing patients with written information prior to the examinations significantly improves their knowledge and experience of the exam procedure.
\end{abstract}

The participation of patients in the MRCPsych examinations is central to the current format of the clinical exam. Although the stressful impact of this experience on the candidate has been documented (Williams et al, 1995; Marcus, 1996), as have the views of the examiners (Mindham, 1995), little attention has been paid to the views of the patients themselves, apart from the study by Persaud et al (1990). This study examined the experiences and views of 21 patients who had participated in the MRCPsych examinations. Prior to participating in the MRCPsych examinations, the patients had received verbal counselling regarding the purpose and format of the examinations. All 21 patients were interviewed after the examination and questioned regarding the purpose of the exam. their knowledge of examination procedure and their personal views of the experience. The results showed that $29 \%(n=6)$ of the patient group found their experience to be distressing. Thirty-eight per cent $(n=8)$ of patients said that they would not like to take part in the examinations again in the future. Despite prior tuition regarding the purpose and format of the examinations $38 \%(n=8)$ patients failed to recall this information subsequently. Nine per cent $(n=2)$ of patients in this study were unaware that participation in the examinations was entirely on a voluntary basis. All patients were pleased about the amount of payment received and the majority of the group had full recollection regarding details of payment. The candidate was viewed positively by most of the patients, although five $(23 \%)$ were surprised by the fact that a physical examination was carried out by the candidate. Interestingly, some patients from this group found the fact that doctors could appear to be nervous rather distressing, although this also allowed them to perceive doctors as being more 'human'. The majority of this patient group described their exam experience positively. Persaud et al (1990) conclude that further research in this area is needed. The purpose of our study was first: to examine patients' experiences during the exam and their knowledge of the exam procedure and second: to investigate if the provision of written explanatory instructions regarding the examination impacted upon their experiences and knowledge.

\section{The study}

In the first part of the study, a 12-item questionnaire was administered to all patients who participated in the membership examinations in two exam centres (St Vincent's Hospital and University College Hospital Galway). All questionnaires were completed anonymously. immediately following the examinations. The questionnaire inquired about the patients' knowledge and experience of the exam procedure, as well as their demographic details and diagnosis. Additionally, patients were invited to suggest ways in which future exams could be improved. Patients in the first group received verbal information only. The same questionnaire was administered to a second patient group, after first giving them similar explanatory instructions, regarding the exam procedure, but in a written format. Analysis of variance, $t$-tests, and chi-squared techniques, with Yates correction where appropriate, were used to compare responses between the two groups.

\section{Findings}

Patient demographic details, gender distribution and diagnoses were very similar for both groups. Patients' responses to questions asked are 
outlined in Table 1 . Sixty-five per cent $(n=26)$ of patients in the group who received verbal preparation only indicated that they had been nervous during the examinations. Seventy-two per cent $(n=29)$ of patients in this group did not know that they might be physically examined as part of the examination procedure. Ten per cent $(n=4)$ of these patients described upsetting experiences. One found the attendance of the College observer 'intimidating'. A second complained that neither of the examiners greeted her when she entered the room 'either verbally or through eye contact or by smiling!'. A third patient indicated that discussing her illness with 'a complete stranger' was upsetting, but added that she was glad she had done so. The fourth patient was unaware that she might undergo physical examination and this upset her greatly at the time.

Following the administration of prior written instructions to the second group, the number of patients who reported that they were nervous during the examinations, $31 \% \quad(n=12)$, was significantly less $(P=0.01)$. There was also a significant reduction in the number of patients who reported that they had been unaware of the physical examination $(15 \%, n=6, P=0.002)$. Only one patient in this group indicated that he had been upset during the exam and attributed this to the fact that the doctor interviewing him asked a whole series of questions very rapidly indeed and I found it very hard to answer him'. While $50 \%(n=20)$ of patients in the verbally prepared group were aware that they would receive payment following the examinations, a much larger proportion $97 \%(n=38)$ of the group who received written preparation, were aware they would receive payment for their participation, though this difference between the two groups is not significant.

The vast majority of participants described the experience as positive. One patient from the group who received verbal instructions only, wrote 'I think the money could have been better' In contrast, a patient from the group who had received written instructions regarding the exam procedure wrote 'I didn't feel payment was necessary as I felt I was helping the doctors', and another, also from this group, wrote 'I would have been quite happy to participate without payment'. One patient wrote 'anything to help the doctors', and another explained she would be delighted to participate in future examinations of this kind as 'Everyone was so kind and polite, it made me feel well and able to cope'.

As regards patient comments on improving the procedure, three patients from the first patient group suggested that patients should not be called too far in advance of the time they were due to go into the exam, and thus avoid having to wait for long periods. A male patient with a diagnosis of mania from the second group requested that the examinations be held in a 'bigger building'. Many of the patients wrote additional comments on the end of their questionnaires praising the smooth and efficient running of the examinations, and affirming that they saw no need to improve the procedure, for example 'I don't think you could improve on anything, the exam was very well organised'.

Table 1. Patients' attitudes and knowledge of the examination

\begin{tabular}{|c|c|c|c|c|c|c|}
\hline & & $\begin{array}{l}\text { Group } 1 \\
\text { Verbal } \\
\text { instruction } \\
n\end{array}$ & (\%) & $\begin{array}{l}\text { Group } 2 \\
\text { Witten } \\
\text { instruction } \\
n\end{array}$ & (\%) & $\mathbf{P}$ \\
\hline Was the candidate polite? & Yes & 40 & $(100)$ & 39 & $(100)$ & NS \\
\hline Were you nervous during the exam? & $\begin{array}{l}\text { Yes } \\
\text { No }\end{array}$ & $\begin{array}{l}26 \\
14\end{array}$ & $\begin{array}{l}(65) \\
(35)\end{array}$ & $\begin{array}{l}12 \\
27\end{array}$ & $\begin{array}{l}(31) \\
(69)\end{array}$ & $0.01^{1}$ \\
\hline $\begin{array}{l}\text { Were you aware you would receive } \\
\text { payment? }\end{array}$ & $\begin{array}{l}\text { Yes } \\
\text { No }\end{array}$ & $\begin{array}{l}20 \\
20\end{array}$ & $\begin{array}{l}(50) \\
(50)\end{array}$ & $\begin{array}{c}38 \\
1\end{array}$ & $\begin{array}{r}(98) \\
(2)\end{array}$ & NS \\
\hline Did you feel payment was sufficient? & $\begin{array}{l}\text { Yes } \\
\text { No }\end{array}$ & $\begin{array}{r}38 \\
2\end{array}$ & $\begin{array}{r}(95) \\
(5)\end{array}$ & $\begin{array}{c}38 \\
1\end{array}$ & $\begin{array}{r}(98) \\
(2)\end{array}$ & NS \\
\hline $\begin{array}{l}\text { Were you aware that you might be } \\
\text { physically examined? }\end{array}$ & $\begin{array}{l}\text { Yes } \\
\text { No }\end{array}$ & $\begin{array}{l}11 \\
29\end{array}$ & $\begin{array}{l}(28) \\
(72)\end{array}$ & $\begin{array}{r}33 \\
6\end{array}$ & $\begin{array}{l}(85) \\
(15)\end{array}$ & $0.002^{2}$ \\
\hline $\begin{array}{l}\text { Did anything upsetting happen during } \\
\text { the exam? }\end{array}$ & $\begin{array}{l}\text { Yes } \\
\text { No }\end{array}$ & $\begin{array}{r}4 \\
36\end{array}$ & $\begin{array}{l}(10) \\
(90)\end{array}$ & $\begin{array}{r}1 \\
38\end{array}$ & $\begin{array}{r}(2) \\
(98)\end{array}$ & NS \\
\hline Did you find the experience positive? & $\begin{array}{l}\text { Yes } \\
\text { No }\end{array}$ & $\begin{array}{r}36 \\
4\end{array}$ & $\begin{array}{l}(90) \\
(10)\end{array}$ & 39 & $(100)$ & NS \\
\hline $\begin{array}{l}\text { Would you participate in exams of this } \\
\text { kind again? }\end{array}$ & Yes & 40 & $(100)$ & 39 & $(100)$ & NS \\
\hline
\end{tabular}




\section{Comment}

Our findings demonstrate that participating in the MRCPsych examinations may be a stressful event for some patients. Despite prior tuition patient participants in our study displayed a considerable lack of knowledge about important aspects of the exam procedure, for example the inclusion of a physical examination. The study by Persaud et al (1990) also found deficiencies in patient knowledge, again despite prior briefing. However, their report of an overall positive response in the patient group towards exam participation was in keeping with the positive views expressed by our own population.

Sixty-five per cent of our verbally prepared group and $31 \%$ of the group who received written preparation reported that they found the examination distressing, as compared to $29 \%$ in the Persaud et al study. Events which patients found to be distressing were, however, comparable in both patient groups. A significant reduction in reported levels of anxiety followed upon receipt of written instructions regarding the exam. All candidates in our study said they would be happy to participate in the exams again if asked, and this finding contrasts with the eight patients $(38 \%)$ of Persaud et als sample who indicated that they would not like to be considered for participation in the examinations again. Although the patients in our study and those in the Persaud et al study had been briefed regarding payment they would receive it is of interest that no patient group had universal recollection of this fact. Patients in both studies thought that the amount of money they received was adequate. In general, both studies revealed that the candidates were viewed positively and with a certain amount of sympathy by the patients.

These results highlight an area of enquiry which has to date been largely neglected. However, our study takes this line of enquiry a step further by investigating the effect of a simple intervention i.e. the provision of written instructions to participating patients on patients' attitudes and knowledge. It would appear to be important to prepare candidates individually for their participation in the examinations. Many of the events which caused anxiety and distress in both patient groups appeared to have their basis in insufficient knowledge. It is worth remembering that despite prior tuition in exam format some patients may still forget certain details. We recommend the provision of written instructions, in addition to the routine assessment of patients' views and experiences following each set of examinations, so that preparation of future participants can become even more efficient.

Patients make an important contribution to the successful running of the MRCPsych examinations. We feel that any study which examines their views and experiences following participation in the examinations will be of benefit not only to exam organisers but also to participating candidates in the future.

\section{Acknowledgements}

We are grateful to Professor T. J. Fahy, Dr P. A. Carney and Dr R. OToole for their assistance with the examinations held in University College Hospital Galway.

\section{References}

MARCUS, L. A. (1996) MRCPsych examinations. Psychiatric Bulletin, 20, 118-119.

MindHAM, R. H. S. (1995) Arrangements for MRCPsych examinations. Psychiatric Bulletin, 19. 448-449.

Persaud, R. D. \& MEUX, C. (1990) Clinical examinations for professional qualification in psychiatry: the patients' views. Psychiatric Bulletin, 14, 65-71.

Williams, C., YeOMANS, D. \& TRIGWELl, P. (1995) Examination techniques. Psychiatric Bulletin, 19. 649.

*Darina Sloan, Senior Registrar in Psychiatry, St Vincent's Hospital, Convent Avenue, Richmond Road, Fairview, Dublin 3; Laura Mannion, Senior Registrar in Psychiatry. University College Hospital Galway; Gregory Swanwick, Senior Registrar in Psychiatry, University College Hospital Galway and James O'Boyle, Consultant Psychiatrist, St Vincent's Hospital, Fairview

*Correspondence 